\title{
The Demography of Drug Abuse in Hong Kong
}

\author{
Tong Liu* ${ }^{*}$ Stuart Gietel-Basten ${ }^{\dagger}$
}

\begin{abstract}
Drug abuse is a critical issue impairing social welfare in many societies. This study explores the demographic characteristics of drug abuse among sub-populations in Hong Kong as a developed and ageing society with large socioeconomic disparities. Significant changes in both the number and rate of drug abuse by drug type, age, gender, ethnicity, education and economic activity are documented during 1991 to 2016. Although narcotics analgesics is more common, stimulants and Ketamine are growing popular in Hong Kong, especially among the youth. The number of elderly drug abusers is increasing due to the ageing population, whereas the rate of elderly drug abuse is actually stable or decreasing. In contrast, drug abuse rate is increasing for the middle-aged and for groups with lower education. The findings support social policy design to curb drug abuse, and call for closer attention to these at-risk groups that are overlooked in Hong Kong.
\end{abstract}

Keywords: drug abuse; substance use; demography; ageing; Hong Kong

\footnotetext{
* Division of Social Science, The Hong Kong University of Science and Technology, Clear Water Bay, Kowloon, Hong Kong. Email: tliuaj@,connect.ust.hk.

$\dagger$ Division of Social Science and Division of Public Policy, The Hong Kong University of Science and Technology, Clear Water Bay, Kowloon, Hong Kong. Email: sgb@ust.hk.
} 


\section{Introduction}

Drug abuse is a critical social issue in many societies worldwide. As a developed economy with large economic disparities among an ageing population, Hong Kong has been facing threats in illicit drug use over the past few decades of rapid development (Cheung and Ch'ien, 1996). Numerous reports and news headlines show an intense pressure in tackling drug deals on the supply side, as well as a growing prevalence of drug use among young people on the demand side (Abdullah et al., 2002; Cheung and Cheung, 2006; Loxton et al., 2008). Addiction to drugs impairs health, work productivity, and family relations in the long run, inducing severe social anxieties and costs (McGrath and Chan, 2005; Shek et al., 2011).

Understanding the situation and trend in drug abuse is vital for social policies to tackle the issue and improve social welfare. Specifically, it is important to determine the rate of change and emergence of new at-risk groups relative to overall changes in the population. These groups may include young adults, female drug abusers including pregnant ones, ethnic minorities and sexual minorities. Taking into account the latest demographic characteristics of drug abusers is crucial for developing social policies to cater for their varying needs, which is highlighted as the first priority in Hong Kong's 2017 Beat Drugs Fund call. ${ }^{1}$

Clearly, this priority is a clarion call for the improved targeting of interventions for groups who are at an increasing risk of drug abuse or who are increasingly falling victim to drug abuse. In other words, this entails exploring whether the number of drug abusers with characteristic $x$ growing more quickly or slowly than the population as a whole with characteristic $x$. It is only when we compare the absolute changes in numbers

\footnotetext{
${ }^{1}$ http://www.nd.gov.hk/en/crda_background.htm.
} 
to overall trends in that population group as a whole can we determine the rate and hence the true extent of changes over time. For example, Hong Kong has one of the most rapidly ageing populations in the world. As such, any increase in the number of older drug abusers would have to be cross-referenced with this population-level change in order to examine the true nature of the trend. Furthermore, there are various social and economic determinants of drug use in Hong Kong (Wu et al., 2014) and elsewhere. As such, it is important to gain a multi-dimensional understanding of the demography of drug abuse in order to design more effective and targeted interventions. Such an improved identification of trends over time will allow for a more accurate representation of trends in reported drug abuse through rates rather than relying on absolute numbers.

However, the extent to which this 'reference to the demographic characteristics of the overall population' has been made in either published reports or the scholarly literature has since been weak. For instance, there were 72 studies supported by the Hong Kong government during 1995-2014, among which 11 reports investigated the trends in number of drug abusers; 30 examined the characteristics of abusers and the role of education; 14 studies evaluated rehabilitation programs; 9 surveyed on public opinion, and 8 studies explored the consequences of drug abuse. In general, there is a lack of study on the changes in drug use rate among different groups. The only reference to the overall population and the irregular Census and Statistics Department 'Feature Articles' is a simple single-year 'Ratio of reported drug abusers to population' (Narcotics Division, 2016). A PubMed search of 'central registry of drug abuse' yields 125 articles, only three studies of which are concerned with the exploration of demographic trends in drug use over time (Cheung and Ch'ien, 1996; Lee et al., 1998; Smart and Murray, 1983). None, however, performs anything akin to a comprehensive analysis of trends and all are at least 
two decades old. There is currently no comprehensive published demographic study of trends in rates of drug abuse in Hong Kong, or in a comparative context. Indeed, owing to data availability, only a handful of 'demographics of drug use' have been published in the literature - most notably the study of drug use in the United States by Kandel (1991).

This paper examines trends in drug abuse in Hong Kong. We aim to construct a 'demography of drug abuse' for Hong Kong, which will identify changes in rates of (different types of) drug abuse by various socioeconomic, geographic and demographic characteristics. This will lay the foundation of future identification of key determinants of drug abuse, and will further support the design and implementation of social policies in tacking drug abuse.

\section{Materials and Methods}

\subsection{Drug Abuse}

Our evidence for understanding the emerging at-risk groups is generally derived from the Central Registry of Drug Abuse (CRDA) at Narcotics Division (ND) in Hong Kong. Since 1972, the CRDA has been the primary source of drug abuse statistics for the Hong Kong government and other key stakeholders (Wat, 1985). The goal of the CRDA has been variously stated but is encapsulated in a report by Legislative Council of Hong Kong (LegCo) as 'facilitating the planning of anti-drug strategies and drug abuse programmes in Hong Kong' (Legislative Council Secretariat, 2009). A primary reason for designing and maintaining the CRDA is to examine changes over time in patterns of drug use. A 2009 iteration of the 'Not Now, Not Ever' drugs campaign led by the then Chief Executive's office highlighted that 'by analysing the statistics and formulating trends of 
drug use, the Government is able to more effectively target resources and formulate programmes to tackle drug abuse'. ${ }^{2}$

Over the past decades, CRDA Reports based on the registry have rightly been the primary source of drug abuse data for both stakeholders and the media (see Narcotics Division, 2016 for the latest report). In addition to this, the Census and Statistics Department has published 'Feature Articles' on the Drug Situation in Hong Kong at irregular intervals, again utilizing the aforementioned CRDA and other data courses (Census and Statistics Department, 2016).

There are 65 reporting agencies in the CRDA system. The reporting agencies include Drug Addiction Treatment Centre of Correctional Services Department, Hong Kong Police Force, Methadone Treatment Programme under Department of Health, Social Welfare Department, Substance Abuse Clinics under Hospital Authority/Hospitals/Clinics, Non-government Organizations (NGOs) (such as Drug Treatment and Rehabilitation Centres, Out-Reaching Teams/Integrated Services Centres, Counselling Centres for Psychotropic Substance Abusers (CCPSA), Centres for Drug Counselling) and schools.

CRDA contains detailed information on age, gender, ethnicity, education, economic activity, district of residence of each individual drug abuser. The illicit drugs can be categorized as narcotics analgesics, stimulants, depressants, tranquillizers, sedatives/hypnotics, hallucinogens, or other drugs. Narcotics analgesics include Opium, heroin, Fentanyl, Pentazocine, Tilidate or Tilidine. Stimulants include Amphetamines, Cocaine, Methamphetamine and anti-depressants. Depressants include Quinalbarbitone, Methaqualone, Meprobamate. Other drugs mainly include Ketamine.

\footnotetext{
${ }^{2}$ https://www.ceo.gov.hk/antidrugs/eng/statistics.html.
} 
Each drug abuser has a unique case number to trace the identity in CRDA data. Some abusers were repeatedly reported by multiple organizations within a year or consecutively over the years, resulting in 666,665 observations of abuse cases in total. We drop the repetitions in reporting within a year. Overall, there were 98,016 drug abusers reported during 1991 to 2016 in Hong Kong.

\subsection{Census}

The Hong Kong Census data covers the 5\% population in 1991, 1996, 2001, 2006, 2011 and 2016. Key information includes age, gender, education, economic activity, district of residence and ethnicity, allowing us to recode the information and match it with the CRDA data.

\subsection{Methods}

The construction of a 'demography of drug abuse' requires the systematic crossexamination of evidence relating to drug abuse (as the numerator) to Census data (as the denominator). This involves the examination of rates of drug abuse (including different types and categories of drug) according to age, gender, ethnicity, education, economic activity and so on.

Specifically, we first explore trends of drug abuse in the CRDA data. Then, we compare them to Census data. As the Census data is only gathered (in effect) every five years, we first interpolate the Census data linearly to obtain annual estimates of population in-between each census point during 1991 and 2016. The population data are then matched with CRDA drug data by year and demographic characteristics, allowing for calculating the rate of drug abuse by these groups. We then examine the changes in numbers and rates of drug abusers in Hong Kong. 


\section{Results}

\subsection{Number of Drug Abusers}

Table 1 summarizes the characteristics of drug abusers in Hong Kong in 1991, 1996, 2001, 2006, 2011 and 2016. In general, most of drug abusers in Hong Kong are Chinese males between 20 to 50 years old, especially the young people. They are not well educated and are likely to be unemployed, with educational attainment below secondary schooling. This depicts the low-income group in Hong Kong. Many of them live in districts with more population density and crime such as Sham Shui Po, Kwun Tong and Yau Tsim Mong, or remote areas such as Yuen Long (as shown later).

The most popular drugs are narcotics analgesics, stimulants and Ketamine. Tranquillizers and hallucinogens are less popular in Hong Kong, contributing only 5.3\% of the total abusers. The popularities of drugs are different between Hong Kong and other countries, as hallucinogens are common but Ketamine are not in the western countries. Depressants, sedatives or hypnotics are totally unpopular in Hong Kong.

[Table 1]

Figure 1 plots the number of drug abusers in Hong Kong during 1991 to 2016. There is a declining trend of drug abuse in Hong Kong over the years. However, there are three major waves with peaks in 1994, 2001 and 2008. The saddle points are in 1992, 1999 and 2006. In these three waves, the number of drug abuse cases would keep increasing for the first two years and then would decline continuously for five years. We also observe a gender difference in that most (80\%) drug abusers are male, and it is the males driving the patterns in drug abuse, while female addiction cases are substantially smaller with a general inverted-U shape. If we further differentiate between newly reported cases with previous ones, the fluctuations in total tolls are seemingly driven by 
new cases each year (as shown by the green dashed line), while there is a continuous decline for the previously reported cases.

\section{[Figure 1]}

The patterns in Figure 1 are likely related with changes in drug demand in Hong Kong, given the consistent efforts by the police department in tackling drug supply. For example, the abuse of ecstasy soared since the year 2000 along with the burgeoning rave party scene in Hong Kong (Narcotics Division, 2011). The consistent drop in the number of reported drug abusers after 2008 is possibly related with the drop in drug demand due to more attention and efforts from the government and NGOs. For instance, a high-level inter-departmental task force, led by the Secretary for Justice, was set up in October 2007 to spearhead government efforts to tackle youth drug abuse. ${ }^{3}$ The ND also commissioned NGOs to provide drug education programs to students from Primary Four to secondary level.

\subsection{Distribution by District}

Figure 2 shows the spatial distribution of drug abusers in Hong Kong. A substantial number of drug abusers live in relatively poor regions with higher population density including Sham Shui Po and Yau Tsim Mong. These regions have many tourists and prostitutes. Drug abusers are also more likely to reside in remote areas with high criminal records, such as Yuen Lung and Tuen Mun. In addition, the number of drug abuse is low in more developed commercial regions on Hong Kong Island, such as Central and Wan Chai. More bars are located in this areas, offering alcohol as a substitute for drugs. These observations are consistent with previous findings on the relationship between drug abuse, education and economic activity (Bachman et al., 2007).

\footnotetext{
${ }^{3}$ https://www.info.gov.hk/gia/general/200710/17/P200710170277.htm.
} 
In general, the number of drug abusers was declining in these hotspots and other districts universally after 2001, as shown by Table 2 .

\section{[Figure 2]}

\section{[Table 2]}

\subsection{Rate of Drug Abuse}

The number of drug abusers offer an overall picture on the drug abuse situation in Hong Kong. This section further explores the demographic patterns of drug abuse in detail with a focus on rate of drug abuse, which is defined as the number of drug abusers per 10,000 people for each demographic category.

\subsubsection{Drug type}

The number of narcotics analgesics abusers has been decreasing for ages below 50 since 1996, as shown by the blue (age 20-30), green (age 30-40) and yellow (age 40-50) lines the left panel of Figure 3a. Similarly, the rate of these drug abusers continuously dropped, as shown by the right panel of Figure 3a. However, the percentage changes in rates are larger than the percentage changes in absolute numbers. This reveals the changes in population structure by age, as the cohort of young people is shrinking due to the ageing population. Before 2006, although the absolute number of drug abusers at 50-60 was growing, the rate of drug abuse remained steady, reflecting that the changes in absolute numbers were mainly due to an increasing population at 50-60. Similarly, more elderly people between 60 and 70 were reported to take narcotics analgesics in the recent decade (shown by the left panel of Figure 3a). If we consider the ageing of population, however, the ratio of these abusers over total number of abusers at $60-70$ remain flat, as shown by the orange line in the right panel of Figure 3a. Similarly, the number remained stable for people above 70 , but the ratio was decreasing due to the growth in population in this 
group. This shows that the increase in number of elderly people taking narcotics analgesics is simply caused by the population structure change rather than that more people in the same cohort above 60 begin to take drugs. In other words, elderly people are unlikely to be newly addicted to drugs.

In Figure 3b, we observe an increasing trend in both absolute number and rate of people taking stimulants above 20 years old, while the elderly people do not prefer stimulants. The number and rate of abusers below 20 years old peaked in 2000 and 2005 , and were continuously dropping afterwards, revealing significant regulatory efforts by the government and other organizations targeted at the youth and students in recent years.

Besides narcotics analgesics and stimulants, most of other drugs is Ketamine, which is prevalent among the youth and middle-aged group. Particularly, the youth has a large share of ketamine abuse (there were over 3,800 ketamine abusers between 10 and 30 years old in 2009). The changes in numbers and trends are different between the youth and middle-aged groups. An increasing number and proportion of people between 30-50 are taking Ketamine during the past 25 years, but the popularity among people between 10-30 was declining since 2009. Again, this may be due to more regulatory and educational efforts in response to the raising alarm of youth taking Ketamine before 2009. In addition, although there were more Ketamine abusers at age 20-30 than those at age 10-20 in 2008 and 2009, the rates of Ketamine abusers at age 20-30 were lower correspondingly (as shown by the peaks in Figure 3c).

Tranquillizers, depressants, hallucinogens, sedatives/hypnotics are unpopular in Hong Kong. Still, we observe heterogeneous patterns in these drugs across different agegroups in Figure 3d and Figure 3e. For instance, tranquillizer abusers show an invertedU shape, with an increasing trend before 2006 and a decreasing trend after 2006. 
Particularly for the age group between 40 and 50 years old, although the absolute number of abusers is relatively stable during 2008 to 2016, the rate of tranquillizer abusers actually increased slightly. This suggests that the middle-aged people are likely to be newly addicted to tranquillizers.

The number and ratio of hallucinogen abusers declined among young people below 30 years old, but are increasing for the middle-aged group between 30 and 50. This may be related with large pressure from work and life for the middle-aged people, who also have higher income compared with the young and the elderly. Cannabis and lysergic acid diethylamide (LSD) are less additive and may cause less harm to them compared with narcotics analgesics and stimulants, therefore the associated costs may be lower for them.

\section{[Figure 3]}

\subsubsection{Age and Gender}

Over $80 \%$ of drug abusers are males, and around $50 \%$ of abusers are between 20 and 40 years old. Although female drug abusers are small in number, the percentage share followed an inverted-U curve, rising from $8.4 \%$ in 1991 to $19.2 \%$ in 2006 , and then dropped slightly to $18.1 \%$ in 2016 .

Figure 4 further picks the age groups of 10-20, 40-50 and 60-70 in the three rows, and compares males on the left panel with females on the right panel. We choose the newly reported cases only to follow the drug abuse changes. The dark solid lines represent total number of drug abusers, and the blue solid lines denote the ratio of drug abusers per 10,000 people. First, as shown by the first row of Figure 4, young people are very responsive in drug abuse, who were driving the peaks in 1994, 2001 and 2008. They contribute to most of the newly reported cases, suggesting that the young people are more 
vulnerable in terms of taking drugs. As shown by previous studies, peer influence, relief of boredom/depression/anxiety, and curiosity are the top three reasons for illicit drug use (Lam et al., 2011). The total number and rate of young drug abusers are rather parallel.

Second, a further investigation by age group reveals a continuous increase in newly reported females between 40 to 50 years old, as shown by the second row of Figure 4. The changes in rates is more significant than the total numbers during 2011 to 2016 , revealing less growth in female population in comparison with the population of female abusers. In comparison, newly reported male abusers between 40 to 50 years old show milder increase with more fluctuations in recent 10 years. This reduces the gaps in numbers of drug abusers between males and females in the middle-aged group, from the gender ratio of 5:1 in 1991 to nearly $2: 1$ in 2016 . The findings reveal a growing concern over drug addiction among the middle-aged group in Hong Kong nowadays. It may be related with more economic social pressure for this group in the past years.

Lastly, the third row of Figure 4 chooses people aged between 60 to 70 as representative of the elderly. The number of newly reported elderly male abusers is declining during 1991 to 2006 but remain stable ever after. In contrast, elderly female drug abusers are small in number and remain relatively stable over the years.

\section{[Figure 4]}

Figure 5 plots the age and gender distribution of overall drug-abuse population per 10,000 people in Hong Kong in each Census year. First, the male drug abuse rate is much higher than females almost at all ages. In particular, most of the elderly above 50 are males. The rates of male abusers at age $20-24$ were over 160 per 10,000 people between 1996 to 2001. As for 2001-2011, the ratio of female abusers at age 10-14 is higher than that of males. This reveals a rising popularity of drugs, mostly Ketamine, 
among the youth during this period. Second, the changes in drug population structure between sexes are similar over the years. For instance, the ratio of drug abusers below 15 years old experienced an increase from 1991 to 2001, and then kept declining after 2001 for both males and females. The drug abuse rate of the elderly above 60 consecutively decreased. The changes in rate of middle aged drug abusers at 30-50 were small after 2001. Overall, the shapes of drug population distribution are similar in 1991 and 2016, with more drops in males at all ages than in females. Many new male abusers at age 2024 were reported in 1996 and 2001. Female distribution follows the shape of pyramids during 1996-2006, with most females at age 15-19 across different age cohorts, exceeding 30 abusers per 10,000 people.

\section{[Figure 5]}

\subsubsection{Ethnicity}

Most of the reported drug abusers in Hong Kong are Chinese, including Hong Kong local residents and residents in Mainland China. However, their share was continuously decreasing from $95.5 \%$ in 1996 to $88.9 \%$ in 2016 . This reflects an increase in migration of people with other ethnicities. In particular, the number of drug abusers is growing for immigrants from South Asia, including Nepal, India, Pakistan, Bangladesh and Sri Lankan. Despite the small numbers, they are increasing rapidly and impose a potential threat on the Hong Kong society. These minorities are more likely to be unemployed and may involve in illicit drug dealing. They also face high social pressure, which could increase the likelihood of taking drugs.

\subsubsection{Education and Economic Activity}

Most of drug abusers have lower or upper secondary education, taking up around $70 \%$ of the total drug abusers (as shown by Table 1 ). Nearly $20 \%$ of drug abusers receive primary 
education only. We select the age-group at 40-50 to construct the rate of drug abusers by education in this group, as their educational attainment is likely stable. Figure 6 plots the number and ratio of drug abusers with primary, lower-secondary, upper-secondary and tertiary education in each row, respectively. Males and females are plotted separately on the left and right column, respectively. We observe a decreasing trend in the number of drug abusers among groups with low-education attainment at primary levels during the past decade. However, the rate of drug abuse for males with primary education is inclining, while female drug abuse rate was declining but increased in 2014. In contrast, the number and ratio of middle-education (lower secondary and upper secondary education) abusers were both increasing. The high-education group with tertiary education remains quantitatively stable over the years. Since higher education is positively correlated with higher income and social status, the drug abuse rate among well-educated people shall be typically lower than that in less educated groups. The increase in middle-education abusers suggests that the social pressure is spreading upward the social hierarchy. These pressures may be related with rising house prices and competition in the labor market, leaving the middle-education group more depressed. The results are consistent with previous empirical and theoretical analyses (Becker and Murphy, 1988).

\section{[Figure 6]}

Economic activity and education are two sides of the same coin. Over half of drug abusers are unemployed or part-time workers. Still, around one third of them are full-time workers, but the rate has been decreasing over the years. The rate of unemployed drug abusers was increasing during 1991 to 2006, and were declining ever after. Part-time workers are becoming more likely to take drugs in Hong Kong. 


\section{Discussion}

Our analyses rest on two fundamental assumptions regarding the completeness of data in both the CRDA and the Census. First, the quality of CRDA data is generally good. Although there have been criticisms of the CRDA data (Siu, 2015), the under-reporting ratio is expected to be low. For instance, for the years 2008 and 2009, the ratios of nonreported abusers to reported abusers were 9.7\% and 7.8\% respectively (Narcotics Division, 2011). Notably, the CRDA data conform to recent scientific studies using wastewater analysis to measure drug use in Hong Kong (Lai et al., 2013). Nevertheless, there is a threat to construct validity (Cook et al., 2002) inasmuch as what is termed 'drug abuser' in this context is in fact the narrower definition of someone who has been registered in the CRDA. As such, we shall be careful in our interpretations to avoid sweeping statements based on what will inevitably be only a partial representation of drug abusers in Hong Kong. Second, there is no reason to suggest that systematic bias exists in under-reporting of particular groups in the CRDA. Therefore, it will not bias our comparisons across different groups.

As with all analyses of rates and determinants, there is a potential threat to statistical conclusion validity. First, the extrapolation between census points may potentially skew the 'population' under analysis. Second, while the CRDA covers a large sample, any exploration of intermediate level rates and subsequent analyses are likely to quickly become beset by the small number problem and hence lose statistical significance. Hence, we avoid large number of small categories in demography and only focus on bigger divisions and their combinations. 


\section{Conclusion}

There is an urgent need to understand the demography of drug abusers by estimating the true drug use rates among sub-populations in Hong Kong. Essentially, identifying the trends and determinants of drug use will enable social policies to target resources to tackle drug use more effectively, particularly to prevent drug use at an early stage.

We find that stimulants and Ketamine are growing popular among the young and middle-aged group in Hong Kong during 1991 to 2016. Given the ageing population, although the number of drug abusers is increasing among the elderly, the rate of drug abuse is stable or decreasing for the elderly group. By contrast, the number and rate of drug abuse is increasing for the middle-aged and for people with medium-level of education (secondary schooling). On average, higher rate of drug abuse is likely associated with lower education and lower income.

Our findings detail a careful profile of the drug-abusing population of Hong Kong. This allows relevant stakeholders to gain a more accurate picture of the 'demography of drug abuse' in Hong Kong. In particular, the drug use among youth has been a focus in the past, whereas the middle-aged and less-educated people received limited policy attention. The findings can further contribute to both more effective interventions in terms of prevention and catering for their varying needs, including but not limited to peer snowballing, closer collaboration with parties in contact with drug abusers in their services for case referral, etc. Future studies could analyze the determinants of drug use in Hong Kong based on the data and findings. 


\section{Acknowledgements}

This work was supported by the Beat Drugs Fund Association under Grant BDF 170062. The authors thank Central Registry of Drug Abuse at Narcotics Division and Census Department of Hong Kong for providing the drug abuse data and census data. The data that support the findings of this study are available upon application to Narcotics Division and Census Department of Hong Kong. The authors claim no conflict of interest. 


\section{References}

Abdullah, A. S. M., Fielding, R., \& Hedley, A. J. (2002). Patterns of cigarette smoking, alcohol use and other substance use among Chinese university students in Hong Kong. American Journal on Addictions, 11(3), 235-246.

Bachman, J. G., O'Malley, P. M., Schulenberg, J. E., Johnston, L. D., Freedman-Doan, P., \& Messersmith, E. E. (2007). The education-drug use connection: How successes and failures in school relate to adolescent smoking, drinking, drug use, and delinquency. Psychology Press.

Becker, G. S., \& Murphy, K. M. (1988). A theory of rational addiction. Journal of Political Economy, 96(4), 675-700.

Census and Statistics Department. (2016). Drug Abuse Situation in Hong Kong. Retrieved from https://www.censtatd.gov.hk/.

Cheung, N. W., \& Cheung, Y. W. (2006). Is Hong Kong experiencing normalization of adolescent drug use? Some reflections on the normalization thesis. Substance use \& misuse, 41(14), 1967-1990.

Cheung, Y. W., \& Ch'ien, J. M. (1996). Drug use and drug policy in Hong Kong: Changing patterns and new challenges. Substance Use \& Misuse, 31(11-12), 15731597.

Cook, T. D., Campbell, D. T., \& Shadish, W. (2002). Experimental and quasiexperimental designs for generalized causal inference. Boston, MA: Houghton Mifflin.

Fazel, S., Bains, P., \& Doll, H. (2006). Substance abuse and dependence in prisoners: a systematic review. Addiction, 101(2), 181-191. 
Horyniak, D., Melo, J. S., Farrell, R. M., Ojeda, V. D., \& Strathdee, S. A. (2016). Epidemiology of substance use among forced migrants: a global systematic review. PLoS one, 11(7), e0159134.

Kandel, D. B. (1991). The social demography of drug use. The Milbank Quarterly, 365414.

Lai, F.Y., Bruno, R., Leung, H.W., Thai, P.K., Ort, C., Carter, S., Thompson, K., Lam, P.K., \& Mueller, J.F. (2013). Estimating daily and diurnal variations of illicit drug use in Hong Kong: a pilot study of using wastewater analysis in an Asian metropolitan city. Forensic Science International, 233(1-3), 126-132.

Lam, C. M., Lau, P. S., Law, B. M., \& Poon, Y. H. (2011). Using positive youth development constructs to design a drug education curriculum for junior secondary students in Hong Kong. The Scientific World Journal, 11, 2339-2347.

Lee, S. S., Hollinrake, J. B., \& Ng, M. H. (1998). Changing behavioural pattern of drug users in Hong Kong 1991-1995. Addiction, 93(4), 541-548.

Legislative Council Secretariat. (2009). The youth drug abuse problem in Hong Kong [IN 12/08-09]. Hong Kong. Retrieved from http://www.legco.gov.hk/yr0809/english/sec/library/0809in12-e.pdf.

Loxton, N. J., Wan, V. L. N., Ho, A. M. C., Cheung, B. K. L., Tam, N., Leung, F. Y., \& Stadlin, A. (2008). Impulsivity in Hong Kong-Chinese club-drug users. Drug and Alcohol Dependence, 95(1-2), 81-89.

McGrath, C., \& Chan, B. (2005). Oral health sensations associated with illicit drug abuse. British Dental Journal, 198(3), 159.

Narcotics Division. (2011). Hong Kong Narcotics and Anti-Money Laundering Report 2007 - 2010. Retrieved from https://www.nd.gov.hk/en/report_2007-10.htm. 
Narcotics Division. (2016). Central Registry of Drug Abuse Sixty-fifth Report. Hong Kong SAR. Retrieved from http://www.nd.gov.hk/en/crda_65th_report.htm.

Shek, D. T., Keung Ma, H., \& Sun, R. C. (2011). A brief overview of adolescent developmental problems in Hong Kong. The Scientific World Journal, 11, 22432256.

Smart, R. G., \& Murray, G. F. (1983). Drug abuse and affluence in five countries: a study of economic and health conditions, 1960-1975. Drug and Alcohol Dependence, 11(3-4), 297-307.

Siu, P. (2015). Hong Kong's illegal drug problem is worse than official numbers suggest: addiction counsellors. Retrieved from http:/www.scmp.com/news/hongkong/article/1828168/hong-kongs-illegal-drug-problem-worse-official-numberssuggest.

Wat, S. (1985). Central Registry of Drug Abuse. The International Journal of the Addictions, 20(2), 279-98.

Wu, C. S., Wong, H. T., Shek, C. H., \& Loke, A. Y. (2014). Multi-dimensional selfesteem and substance use among Chinese adolescents. Substance Abuse Treatment, Prevention, and Policy, 9(1), 42. 


\section{Tables}

Table 1. Number of Drug Abusers in Hong Kong

\begin{tabular}{|c|c|c|c|c|c|c|}
\hline & 1991 & 1996 & 2001 & 2006 & 2011 & 2016 \\
\hline Population $(1,000)$ & 5,752 & 6,436 & 6,714 & 6,857 & 7,072 & 7,337 \\
\hline Number of drug abusers & 15,263 & 19,673 & 18,513 & 13,252 & 11,572 & 8,239 \\
\hline Rate (per 10,000 ) & 27 & 31 & 28 & 19 & 16 & 11 \\
\hline Newly reported (\%) & 17.7 & 21.9 & 30.5 & 26.5 & 28.2 & 24.6 \\
\hline Previously reported (\%) & 82.3 & 78.1 & 69.5 & 73.5 & 71.8 & 75.4 \\
\hline \multicolumn{7}{|l|}{ Drug Type(\%) } \\
\hline Narcotics Analgesics & 82.0 & 81.1 & 61.6 & 59.7 & 50.7 & 47.7 \\
\hline Stimulants & 0.1 & 2.2 & 13.7 & 14.8 & 16.6 & 31.1 \\
\hline Others (Ketamine) & 1.5 & 2.7 & 7.0 & 15.3 & 27.4 & 13.0 \\
\hline Depressants & 0.2 & 0.1 & 0.0 & 0.2 & 0.0 & 0.0 \\
\hline Tranquillizers & 0.8 & 1.5 & 1.0 & 5.2 & 2.5 & 2.1 \\
\hline Sedatives/Hypnotics & 0.0 & 0.0 & 0.2 & 0.4 & 0.5 & 0.5 \\
\hline Hallucinogens & 2.2 & 6.3 & 3.4 & 3.9 & 1.8 & 3.2 \\
\hline \multicolumn{7}{|l|}{$\operatorname{Age}(\%)$} \\
\hline $10-20$ & 7.4 & 15.2 & 17.6 & 16.7 & 14.5 & 4.8 \\
\hline $20-30$ & 26.9 & 29.7 & 32.7 & 26.1 & 25.5 & 23.3 \\
\hline $30-40$ & 31.4 & 23.5 & 19.8 & 23.3 & 25.3 & 26.4 \\
\hline $40-50$ & 18.1 & 20.6 & 17.8 & 17.2 & 16.0 & 23.5 \\
\hline $50-60$ & 8.5 & 6.2 & 8.7 & 13.0 & 13.4 & 13.4 \\
\hline $60-70$ & 5.7 & 3.6 & 2.4 & 2.7 & 4.6 & 7.3 \\
\hline $70+$ & 1.9 & 1.2 & 0.9 & 0.9 & 0.7 & 1.3 \\
\hline \multicolumn{7}{|l|}{ Gender(\%) } \\
\hline Male & 91.6 & 87.6 & 84.5 & 80.8 & 81.5 & 81.9 \\
\hline Female & 8.4 & 12.4 & 15.5 & 19.2 & 18.5 & 18.1 \\
\hline \multicolumn{7}{|l|}{ Ethnicity(\%) } \\
\hline Chinese & & 95.5 & 95.3 & 91.4 & 91.7 & 88.9 \\
\hline Nepalese & & 0.6 & 1.1 & 1.3 & 2.6 & 3.4 \\
\hline \multicolumn{7}{|c|}{ Indian/Pakistani/Bangladeshi/Sri } \\
\hline Vietnamese & & 1.9 & 1.5 & 1.9 & 1.8 & 2.5 \\
\hline Other & & 1.8 & 1.9 & 4.9 & 2.9 & 2.0 \\
\hline \multicolumn{7}{|l|}{ Education(\%) } \\
\hline No schooling/kindergarten & 5.7 & 4.3 & 1.9 & 1.7 & 1.1 & 1.4 \\
\hline Primary & 45.2 & 34.6 & 26.0 & 26.3 & 20.9 & 17.0 \\
\hline Lower secondary(S1-S3) & 32.6 & 47.6 & 50.3 & 50.1 & 51.8 & 44.4 \\
\hline Upper secondary(S4-S7) & 9.6 & 11.3 & 18.0 & 18.1 & 20.8 & 21.6 \\
\hline Tertiary & 0.5 & 0.7 & 0.8 & 1.0 & 1.7 & 2.8 \\
\hline \multicolumn{7}{|l|}{ Economic Activity(\%) } \\
\hline Unemployed & 31.7 & 43.2 & 45.6 & 50.1 & 44.6 & 41.0 \\
\hline Full-time workers & 62.5 & 42.8 & 34.7 & 29.8 & 31.8 & 27.7 \\
\hline Casual/part-time worker & & 7.9 & 6.8 & 7.3 & 11.3 & 10.6 \\
\hline Workers in illicit trade & & 0.3 & 0.5 & 1.0 & 0.9 & 0.9 \\
\hline
\end{tabular}




\begin{tabular}{|c|c|c|c|c|c|c|}
\hline Home-makers & & 0.7 & 1.3 & 1.4 & 1.7 & 2.2 \\
\hline Students & & 1.9 & 4.9 & 4.6 & 3.9 & 1.1 \\
\hline Retired persons & & 1.0 & 1.4 & 1.4 & 1.9 & 2.6 \\
\hline Others & & 0.4 & 0.3 & 0.3 & 0.1 & 0 \\
\hline Unknown & 5.9 & 1.7 & 4.7 & 4.1 & 3.8 & 13.9 \\
\hline
\end{tabular}

Note: Number and percentage of drug abusers by different categories are listed. 
Table 2. Number of Drug Abusers in Hong Kong Districts

\begin{tabular}{|c|c|c|c|c|c|c|c|}
\hline District & 1991 & 1996 & 2001 & 2006 & 2011 & 2016 & $\begin{array}{l}2016 \\
(\%)\end{array}$ \\
\hline Sham Shui Po & 1,583 & 1,787 & 1,656 & 1,322 & 1,194 & 874 & 10.61 \\
\hline Kwun Tong & 1,866 & 2,294 & 1,799 & 1,248 & 993 & 768 & 9.32 \\
\hline Yau Tsim Mong & 1,489 & 1,766 & 1,584 & 1,184 & 877 & 725 & 8.80 \\
\hline Yuen Long & 652 & 1,156 & 1,268 & 928 & 1,120 & 713 & 8.65 \\
\hline Kwai Tsing & 972 & 984 & 1,110 & 793 & 838 & 584 & 7.09 \\
\hline Tuen Mun & 954 & 1,686 & 1,407 & 1,054 & 827 & 566 & 6.87 \\
\hline Wong Tai Sin & 1,513 & 1,777 & 1,426 & 899 & 634 & 456 & 5.53 \\
\hline Sha Tin & 624 & 1,001 & 1,046 & 789 & 618 & 404 & 4.90 \\
\hline North & 424 & 705 & 776 & 643 & 661 & 384 & 4.66 \\
\hline Eastern & 842 & 1,186 & 1,064 & 665 & 588 & 380 & 4.61 \\
\hline Kowloon City & 775 & 871 & 872 & 463 & 366 & 310 & 3.76 \\
\hline Tsuen Wan & 508 & 1,009 & 845 & 509 & 381 & 275 & 3.34 \\
\hline Tai Po & 358 & 739 & 753 & 579 & 531 & 288 & 3.50 \\
\hline Sai Kung & 129 & 340 & 492 & 349 & 329 & 259 & 3.14 \\
\hline Islands & 82 & 182 & 158 & 245 & 330 & 209 & 2.54 \\
\hline Southern & 566 & 825 & 773 & 555 & 374 & 187 & 2.27 \\
\hline Wan Chai & 429 & 453 & 405 & 247 & 156 & 117 & 1.42 \\
\hline Central \& Western & 336 & 409 & 440 & 219 & 179 & 71 & 0.86 \\
\hline Unknown & 1,161 & 503 & 639 & 561 & 576 & 669 & 8.12 \\
\hline
\end{tabular}




\section{Figures}

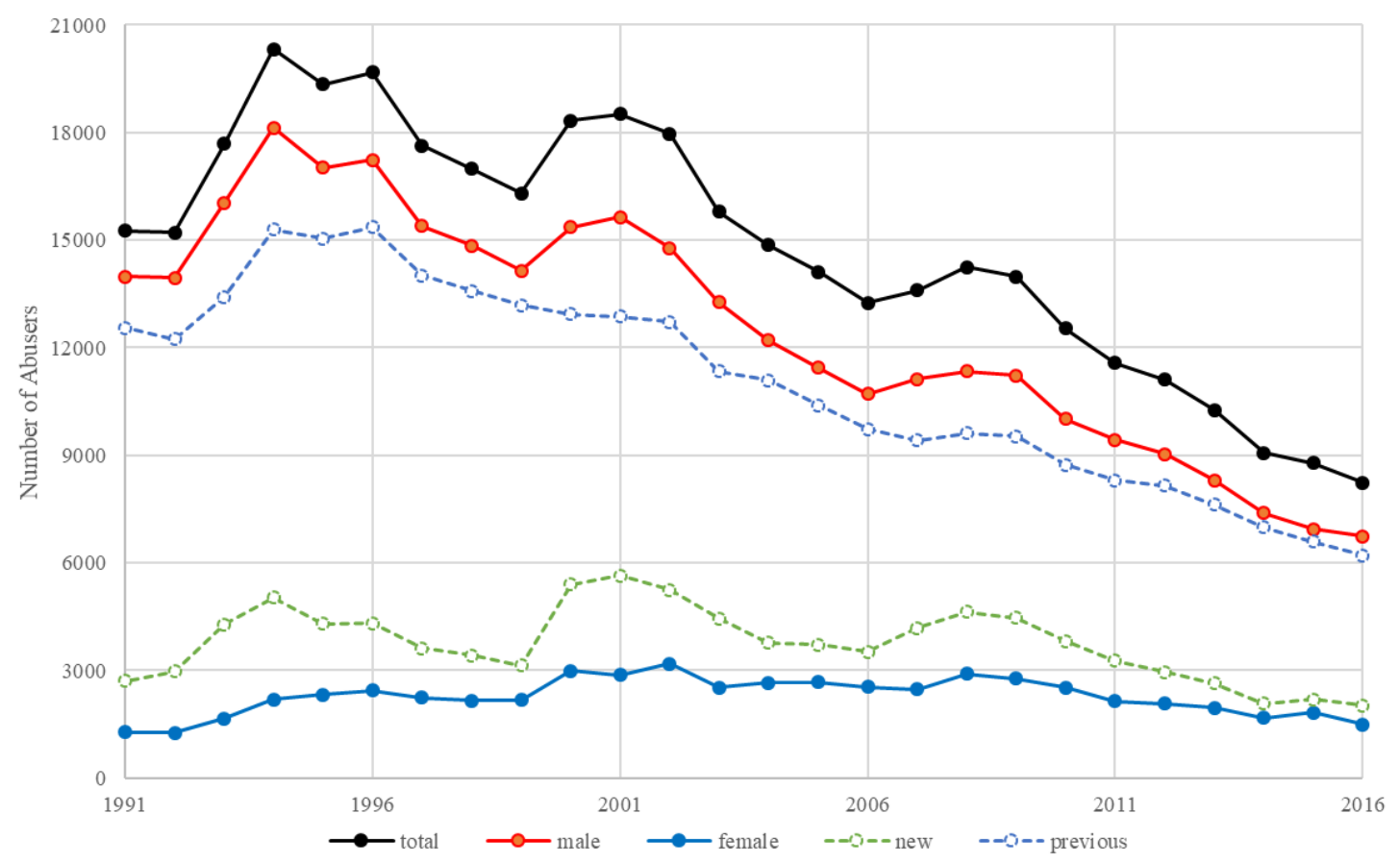

Figure 1. Number of Drug Abusers in Hong Kong in 1991-2016

Note: The black solid line presents the total number of drug abusers. The red and blue solid line show male and female drug users, respectively. The green and blue dashed line show the drug abusers that are previously or newly reported, respectively. 


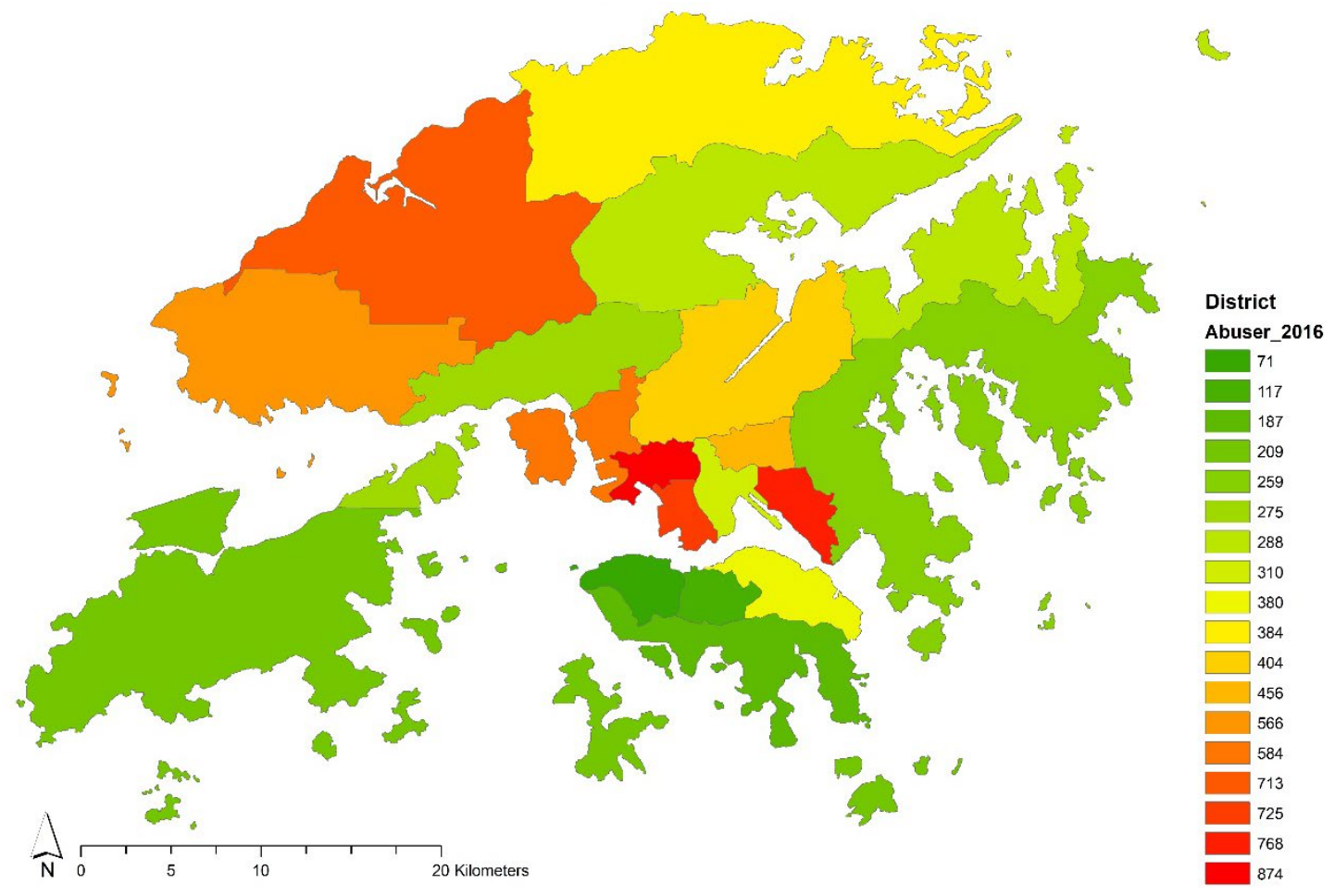

Figure 2. Distribution of Drug Abusers by Hong Kong District in 2016

Note: The number of drug abusers in each of 18 Hong Kong districts in 2016 is shown with darker green colors indicating smaller numbers and darker red colors indicating larger numbers. 


\section{Narcotics Analgesics}

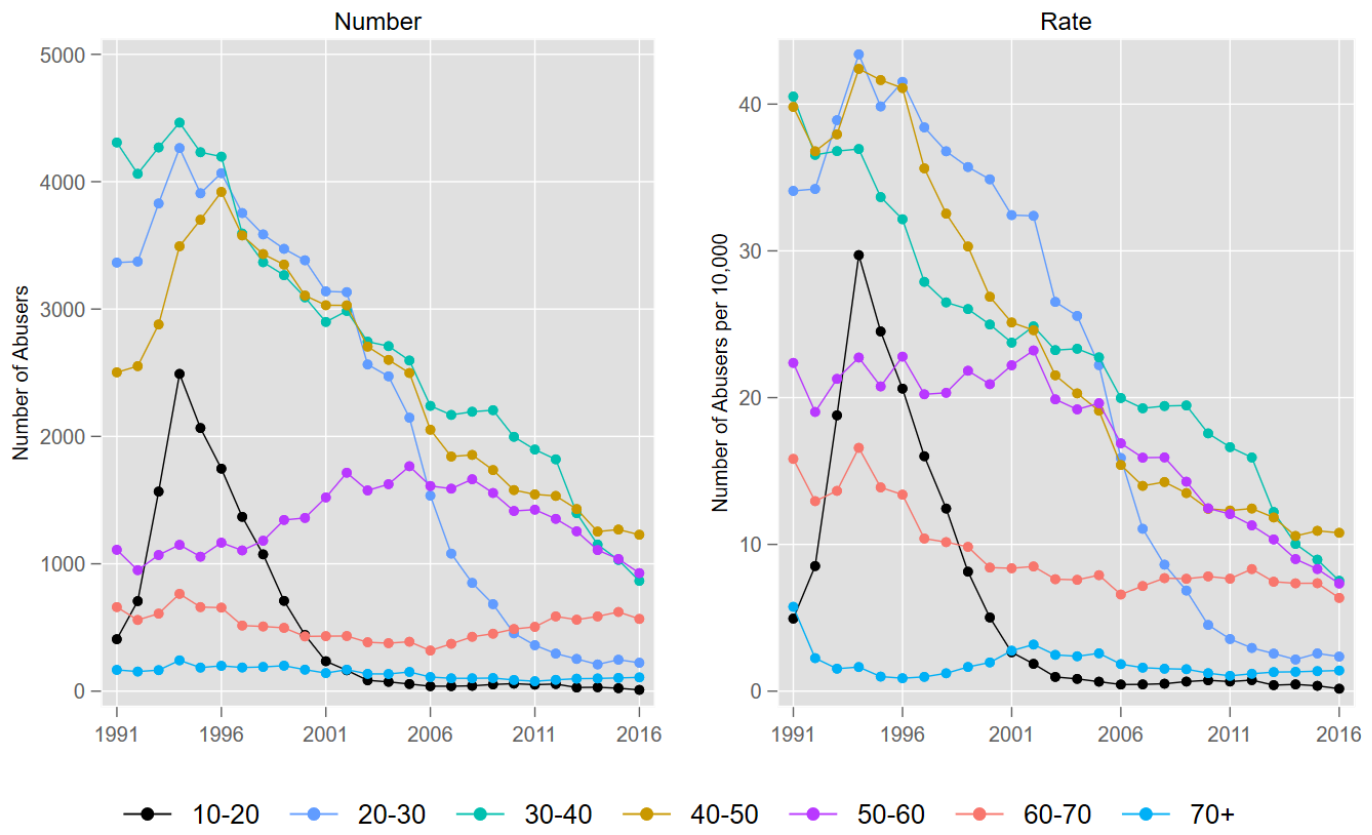

Figure 3a. Narcotics Analgesics

\section{Stimulants}
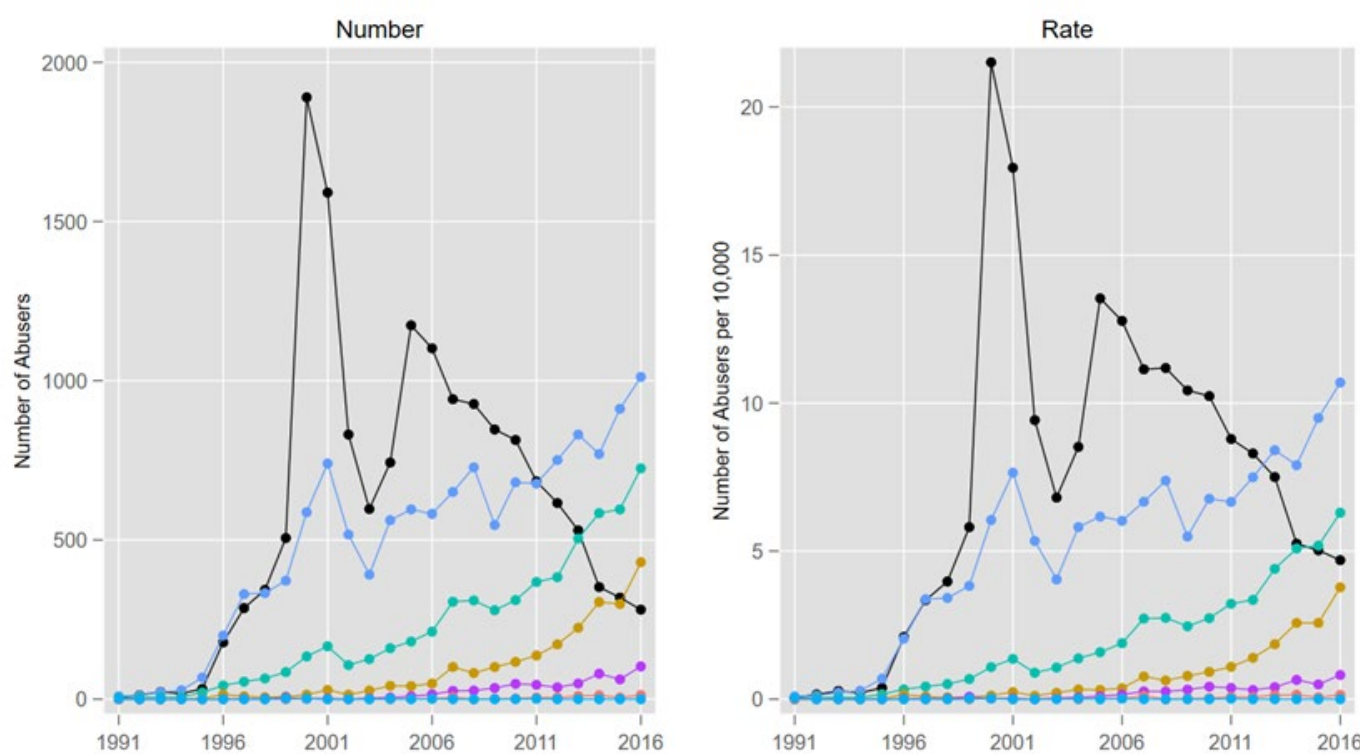

$\bullet 10-20 \rightarrow 20-30 \rightarrow 30-40 \rightarrow 40-50 \rightarrow 50-60 \rightarrow 60-70 \rightarrow 70+$

Figure 3b. Stimulants 


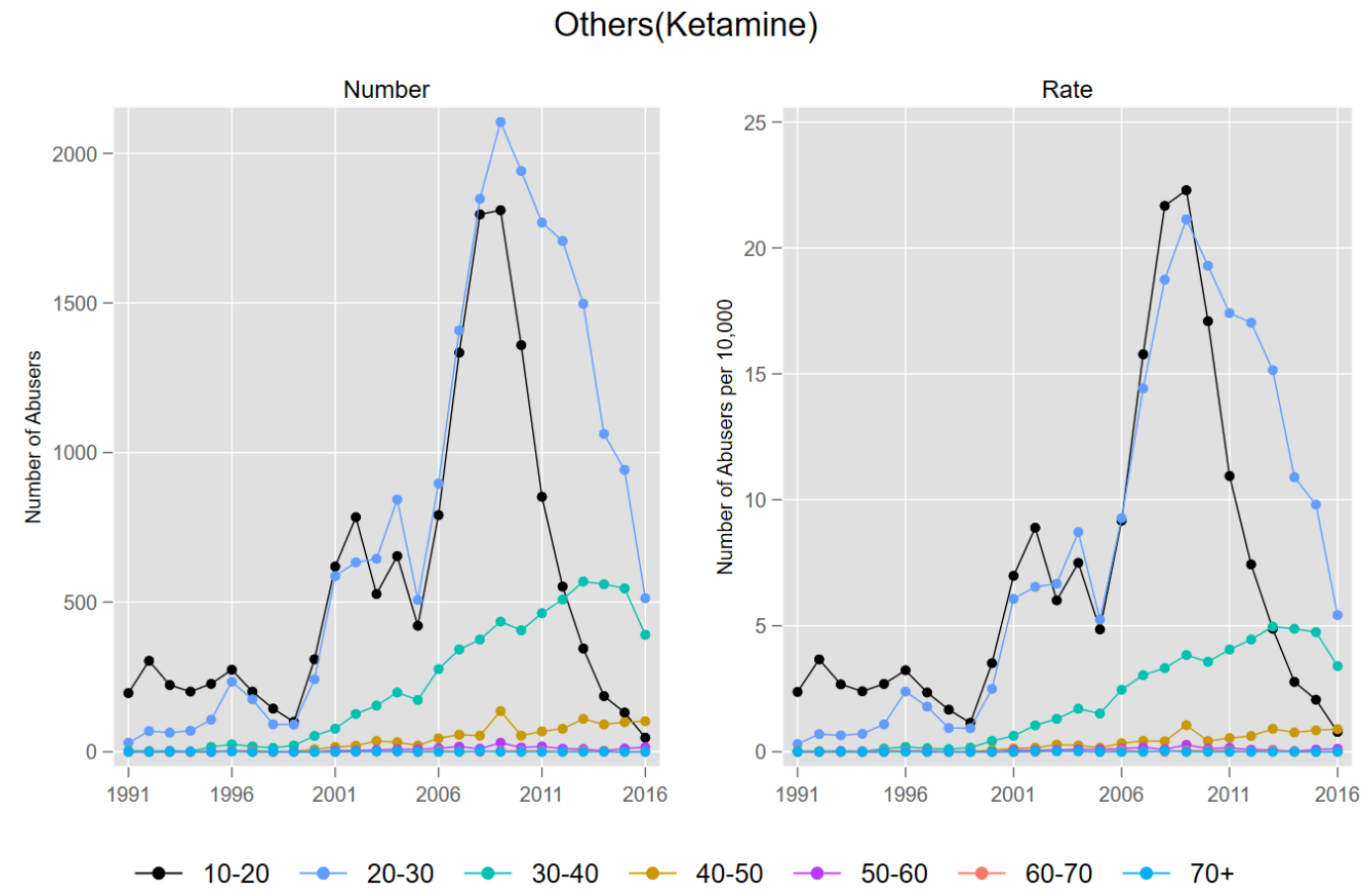

Figure 3c. Others (Ketamine)

Tranquillizers

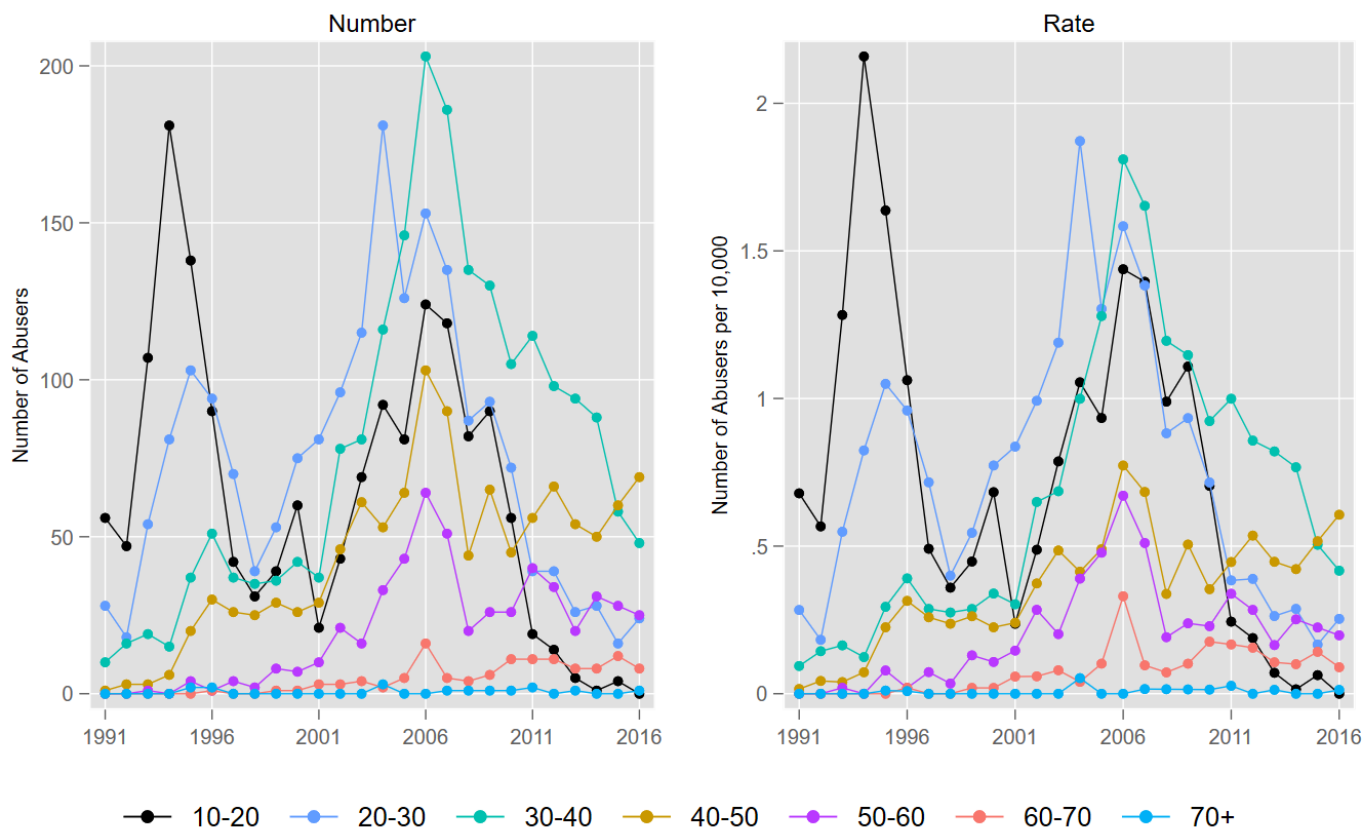

Figure 3d. Tranquillizers 


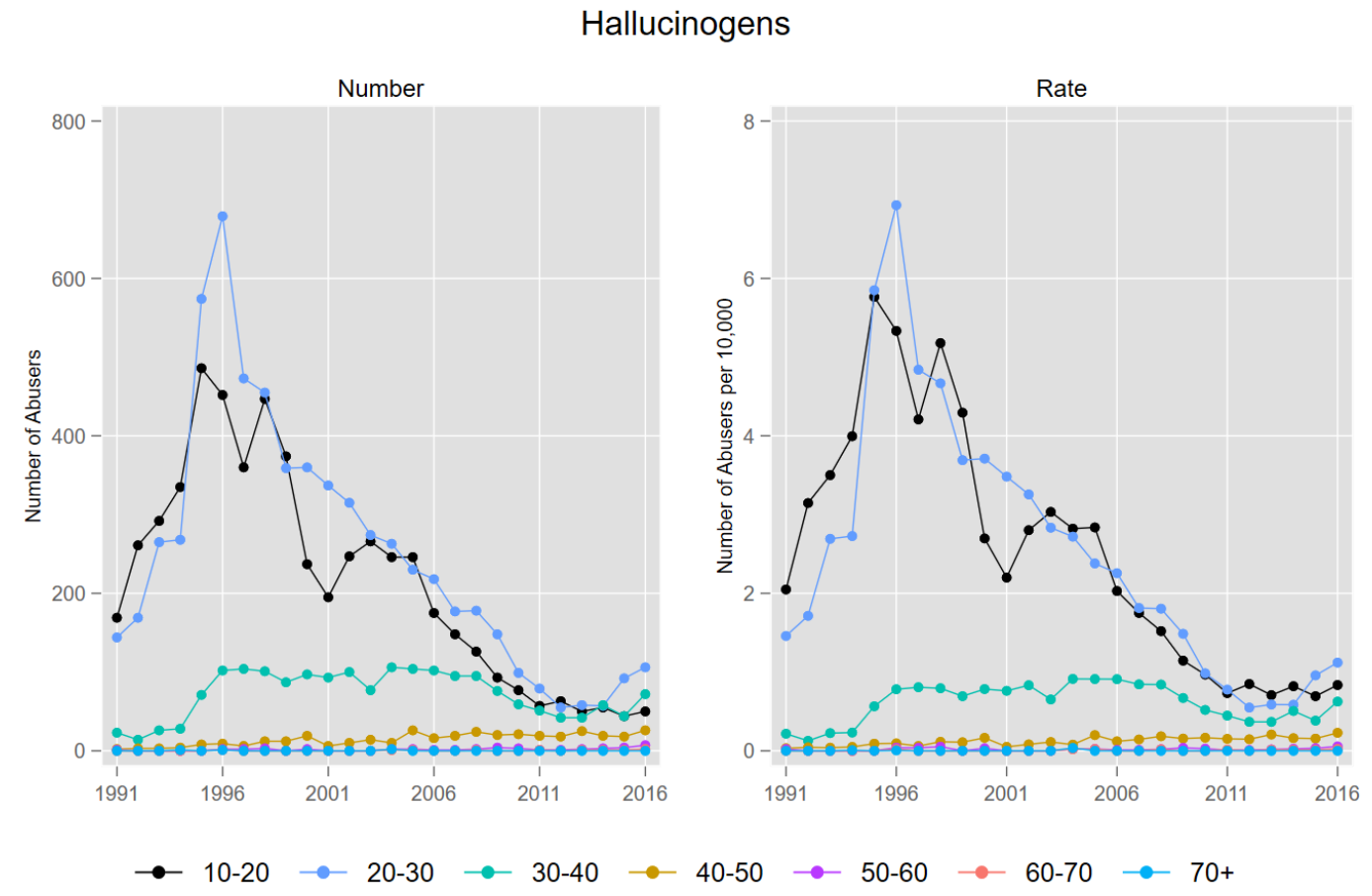

Figure 3e. Hallucinogens

Figure 3. Number and Ratio of Abusers by Drug Type

Note: Number and ratio of drug abusers by age-group are plotted for narcotics analgesics, stimulants, others (Ketamine), tranquillizers, and hallucinogens, respectively. 

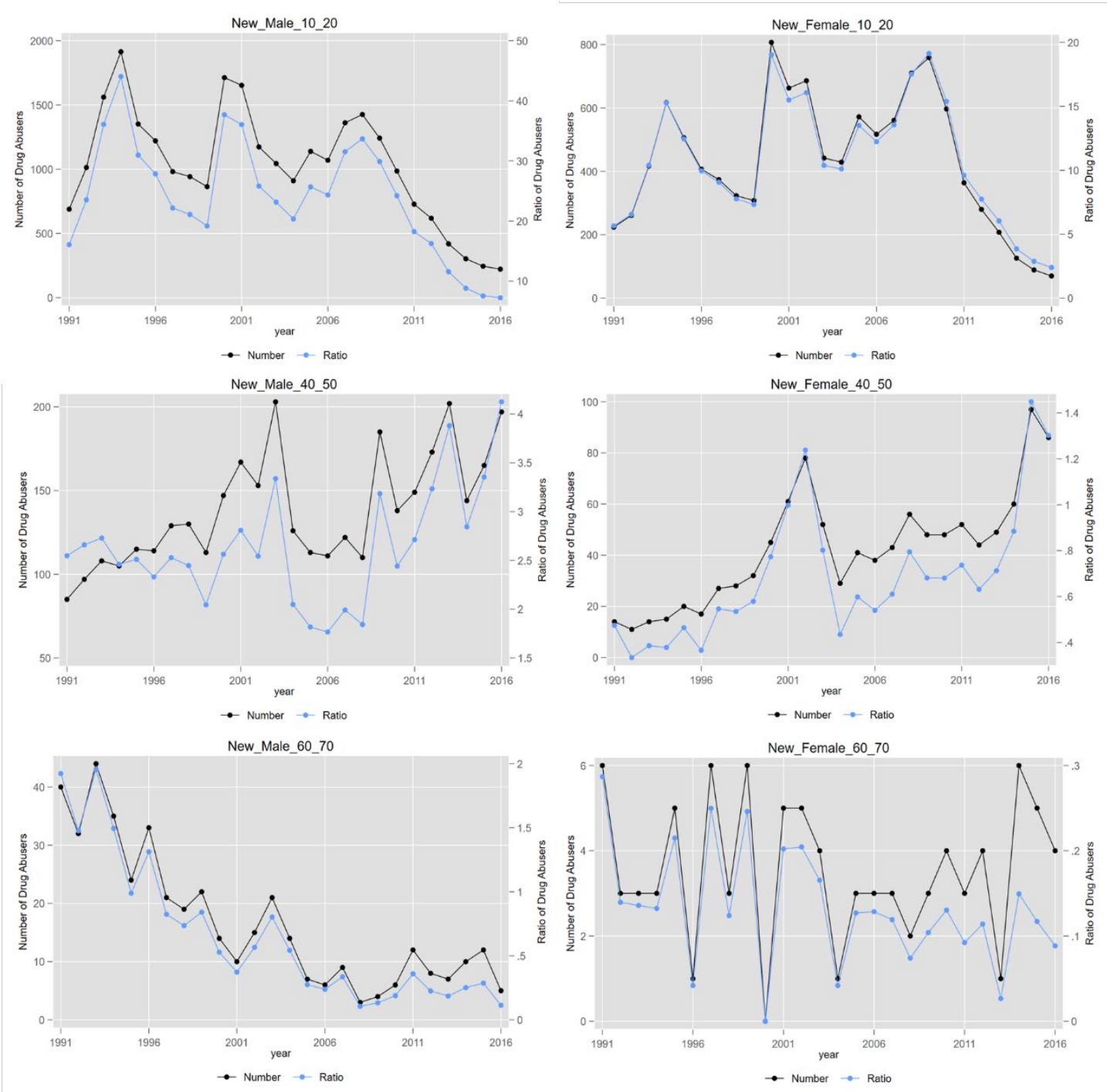

Figure 4. Number of New Drug Abusers by Age and Gender

Note: Newly reported drug abusers by gender and age were shown. Males are on the left panel, while females are on the right panel. The 10-20, 40-50 and 60-70 age groups are plotted in each row. The dark solid lines represent total number of drug abusers, and the blue solid lines denote the ratio of drug abusers per 10,000. 

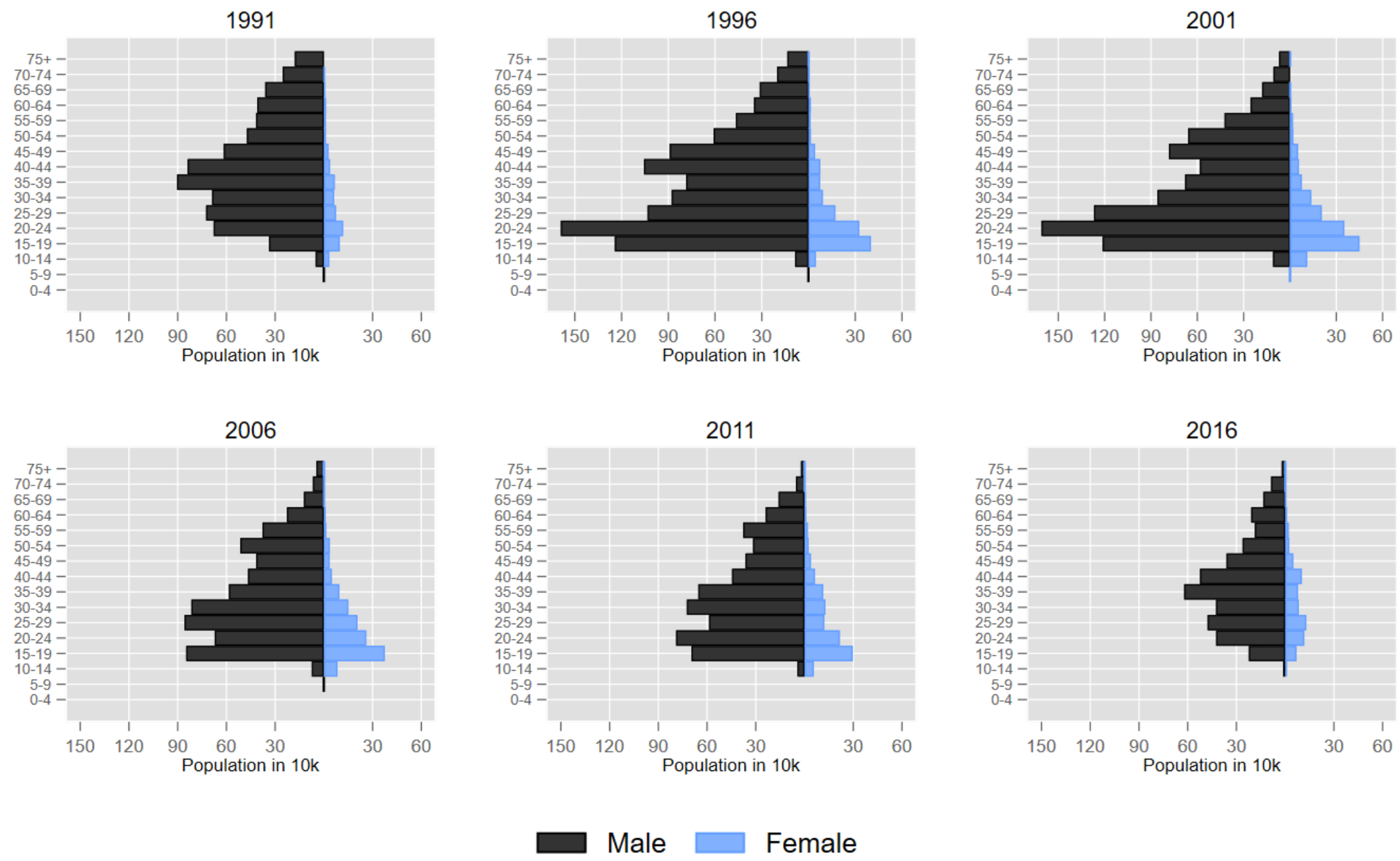

Figure 5. Rate of Drug Population by Age and Gender

Note: Number of drug abusers per 10,000 by age and gender is plotted for each year in 1991, 1996, 2001, 2006,2011 and 2016 in Hong Kong. 

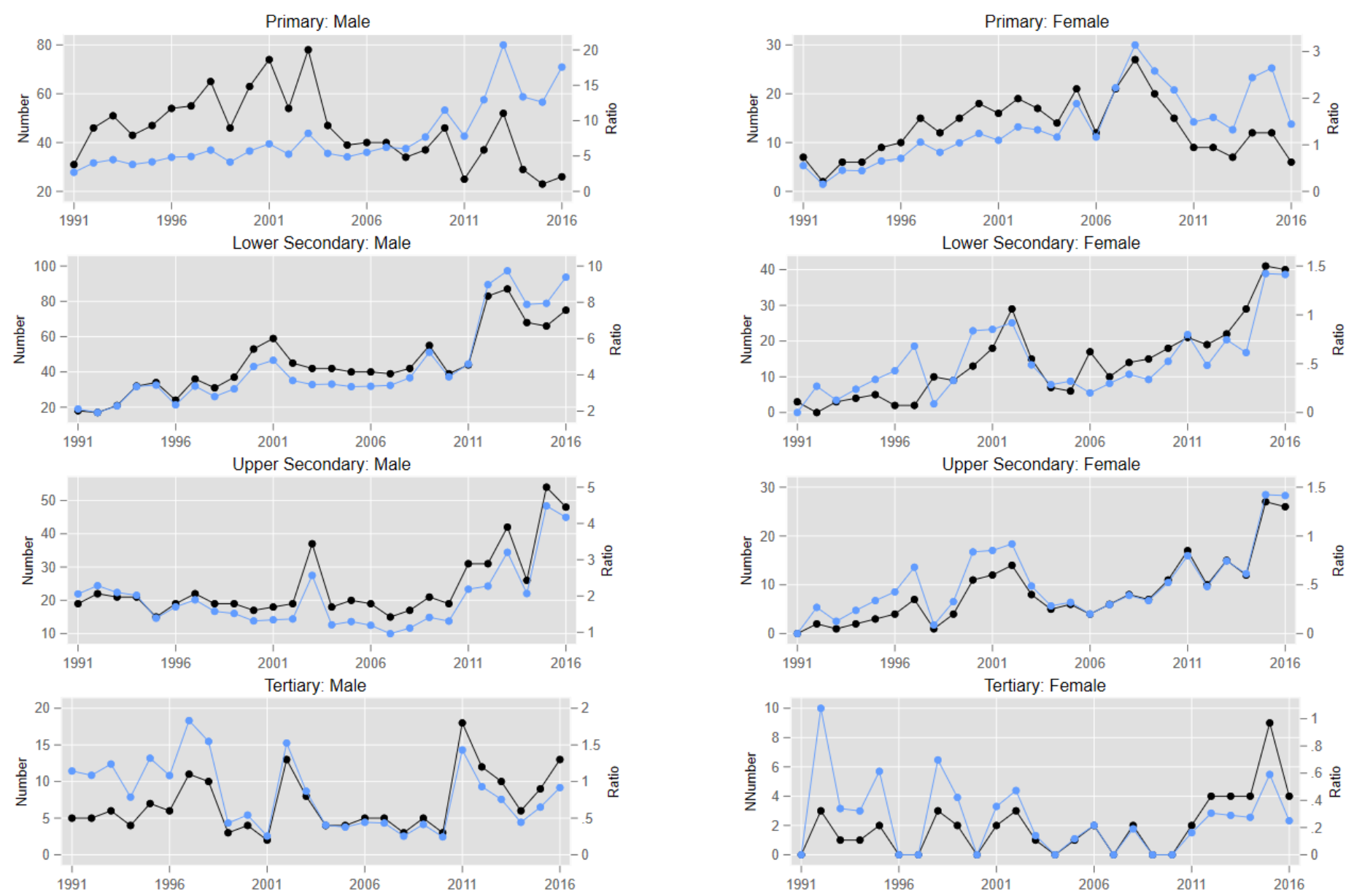

$\rightarrow$ Number $\rightarrow$ Ratio

Figure 6. New Drug Abusers by Education at Age 40-50

Note: Newly reported drug abusers by gender and educational attainment were shown. Females and males are on the left and right panel, respectively. The people are aged $40-50$. 